\title{
COVID-19 as a nonprofit workplace crisis: Seeking insights from the nonprofit workers' perspective
}

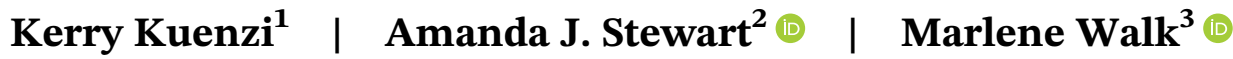

${ }^{1}$ Public and Environmental Affairs, University of Wisconsin Green Bay, WI, USA

${ }^{2}$ Department of Public Administration, North Carolina State University, Raleigh, NC, USA

${ }^{3}$ Paul H. O'Neill School of Public and Environmental Affairs, Indiana University-Purdue University Indianapolis, Indianapolis, IN, USA

\section{Correspondence}

Amanda J. Stewart, North Carolina State University, 212 Caldwell Hall, Campus Box 8102, Raleigh, NC 27695-8102.

Email: ajstewa5@ncsu.edu

Funding information

2020 RGK-ARNOVA President's Award

\begin{abstract}
Due to the COVID-19 pandemic, nonprofit organizations face increased demands for services alongside decreased revenues and must make tough choices on how to weather these stressors. Alongside these organizational changes, COVID-19 impacts nonprofit workers and could be a career shock for these individuals, potentially altering how they think of their work and career intentions, even jeopardizing their commitment to the sector. Therefore, this paper outlines a research agenda to understand how the pandemic impacts nonprofit workers and their commitment to working in the sector. Several areas for future research are identified including human resource policy, leadership development, generational differences, gender effects, nonprofit graduate education, and mission-specific work effects.

\section{K E Y W O R D S}

COVID-19, critical incidents, nonprofit sector commitment, organizational change
\end{abstract}

\section{1 | INTRODUCTION}

Nonprofit organizations are frequently called upon and play vital roles during times of crisis (Simo \& Bies, 2007). What is different during the COVID-19 pandemic is that many nonprofit organizations "are struggling with how to help their communities while also trying to endure

The authors are listed alphabetically as they are sharing equal authorship for this manuscript. 
the crisis themselves" (BoardSource, 2020). Even though the nonprofit sector reacts to social, political, organizational, and personal forces on a regular basis, the pandemic is unprecedented in the breadth and magnitude of these forces happening simultaneously. Narrowing in at the organizational level, nonprofits across the United States have reported operational fallout from the pandemic, including weakened revenue streams and heightened demand for services and supports. Early evidence also indicates that not all mission subsectors have fared the same with variations existing according to the subsector's programming, populations served, and even revenue sources (Kim \& Mason, 2020; Newhouse, 2020a). To mitigate these strains on programming, service delivery, and organizational viability, nonprofits are implementing cost-saving strategies such as changes to staffing including layoffs, furloughs, and reduced work hours. Yet, these choices impact the sector's 12.3 million paid workers (Salamon \& Newhouse, 2019), especially those who work for organizations offering direct services, such as food banks, homeless shelters, or workforce development; precisely, the organizations that are most likely to face a perfect storm of increasing demand for services and decreasing revenues. Indeed, Salamon and Newhouse (2020) estimate that 1.6 million nonprofit jobs (13\%) have already been lost between March and May 2020. Some of those jobs were recovered in June 2020, but by October 2020, the sector still has 900,000 fewer jobs compared to February 2020 (Newhouse, 2020a), and, with the current speed, full recovery could take another 2.3 years (Newhouse, 2020b).

Although there is still uncertainty stemming from COVID-19, what is clear is that COVID-19 will have long-term impacts for nonprofits and their staff for some time to come. We posit the COVID-19 pandemic as a critical incident that alters the landscape of our sector's workforce-one that will reverberate back into the organizations themselves, since nonprofits heavily rely on their human resources for their mission provision (Mesch, 2010; Walk, Schinnenburg, \& Handy, 2014). Although the pandemic is not the first incident to affect the nonprofit sector (it is after all referred to as the "resilient sector" [Salamon, 2003]), the longhaul nature of the pandemic, inclusive of its constricting safety protocols and economic repercussions, has presented unprecedented environmental stressors for these organizations. We therefore ask: In the wake of COVID-19 and the related organizational changes, how will the nonprofit sector be able to attract and retain employees, ensuring the sector's stability and function as a social safety net? In the following, we issue a call for research into how organizational changes made in response to COVID-19 affect the nonprofit workforce. Our research encourages attention be paid to how the intersection of social, political, organizational, and personal changes brought on by COVID-19 may impact the nonprofit workforce and, by extension, the sector. We understand the concept of sector commitment as a fruitful lens for identifying who is committed to the nonprofit sector now and in the future, and we frame this concept as a means for understanding the pandemic's impact on the nonprofit sector's workforce as it copes with the pandemic and rebuilds in a post-pandemic world.

\section{2 | NONPROFIT SECTOR COMMITMENT}

For a sector once known as the voluntary sector, the mission fields that comprise the nonprofit sector are now dependent on their paid workforce. While there are certainly individuals who work in the sector without concern or knowledge of its nonprofit nature, many individuals seek careers in the nonprofit sector based on their commitment to mission-related work or an aptitude toward public or community service (Johnson \& Ng, 2016; Tschirhart, Reed, Freeman, \& Anker, 2008). Sector plays a role in an individual's "career choices" as workers look for 
positions or organizations based on the values and missions the sector serves (Tschirhart et al., 2008), but a "commitment to remain" in a particular sector signals a more enduring quality (Tschirhart et al., 2008, p. 670). Therefore, we define nonprofit sector commitment as the strength of an individual's identification with and involvement in the nonprofit sector. Said another way, sector commitment refers to a dedication to stay, while sector choice is about an initial engagement or entrance to the sector. Most often sector choice and sector commitment are aligned, but as we discuss below, there are cases in which this is not the case. Given the sector's dependence on its workforce, these committed nonprofit workers are a promising prospect for leadership development and cultivation. Yet, sector choice and commitment are complex phenomena that may be impacted by different factors including external events and career shocks.

Weisbrod's (1988) theory of managerial sorting posits that professionals seek to align with their sector of employment, which is influenced by their motivations, preferences, and goals. From this, extrinsic and intrinsic motivations both fuel sector choice and commitment (for a compilation of this research, refer to Walk, Stewart, \& Kuenzi, 2020). Findings from studies of nonprofit workers suggest that many individuals currently working in the sector seek out these positions intentionally (Stewart \& Kuenzi, 2018) with a strong desire to remain in these positions regardless of other mitigating factors or opportunities (Walk et al., 2020). However, evidence documents commitment can change over time (citation redacted for peer review), and we are concerned that nonprofit workers may encounter factors, such as prolonged uncertainty, COVID-19 related trauma, even concomitant concerns from the pandemic coupled with widespread social unrest that distract them from their commitment, prompting them to leave the sector for other career prospects.

From a study of nonprofit graduate alumni, workers who were fully committed to the nonprofit sector also expressed high extrinsic work expectations (Walk et al., 2020), which should be concerning, as individuals tend to leave their nonprofit careers because of the organizations' inability to offer competitive wages (Kim \& Charbonneau, 2018; Ng \& McGinnis Johnson, 2019). This finding is especially evident for those in leadership positions who are tempted by compensation in the for-profit sector (Johnson \& Ng, 2016), and for the Millennial generation-the largest in the current workforce and those whose long-term career trajectories are very likely to be impacted by COVID-19-who may let compensation drive decisions to switch employers or leave the sector entirely (AbouAssi, McGinnis Johnson, \& Holt, 2019; Johnson \& Ng, 2016; Walk et al., 2020). Furthermore, findings indicate that about a third of those fully committed to the nonprofit sector do not, in fact, work in it (Walk et al., 2020). This indicates that individuals can be committed to a sector of employment without working in it, suggesting that sector commitment and sector choice (e.g., nonprofit employment) are not the same. Other factors including employee benefits, most importantly health care (or the lack thereof) (Miller, 2020), professional development opportunities (Linscott, 2011), and financial burdens such as student debt also impact sector and career decisions (Berkshire, 2012). With this compiling evidence about factors that shape an individual's commitment to the nonprofit sector, the critical incident of a pandemic should be anticipated as both a singular and compounding factor influencing how nonprofit workers think about their work in the sector. Moreover, this sector commitment literature typically treats the sector's workers as uniform, but in the heterogeneous nonprofit sector, the uneven effects of the pandemic may cause some workers' commitment to be affected differently than other workers.

Thus, nonprofit sector commitment should be investigated in light of organizational changes introduced during the pandemic to the nonprofit workforce and workplaces. 
We connect two theoretical lenses beneficial for this inquiry. First, we posit COVID-19 as a critical incident bound to shape worker outlooks as they emerge from this crisis and plan for their future. Previous research and theorizing in psychology and careers have sought to understand how the impact of "critical incidents" such as a personal crisis, economic recession, or in this current context, a pandemic, shape professional career paths (Bright, Pryor, \& Harpham, 2005). This research conceives that a worker's decisions about their career are not strictly based on rational decision-making, but also influenced by chance events (Bright et al., 2005). In the nonprofit context, several researchers have investigated the role of chance events in nonprofit career decision-making (Flanigan, 2010; Nelson, 2018; Schlosser, McPhee, \& Forsyth, 2017), but this research is limited to how these incidents influence the decision to opt into the nonprofit sector, organization, or position (i.e., sector choice), not how chance events effect how workers think about staying in the nonprofit sector (i.e., sector commitment). Further sector choice and commitment have been used as one and the same in prior literature, yet a chance event may pose a trigger that someone may still have nonprofit sector commitment but be led to make a choice that directs them to a different sector (e.g., being laid off from a nonprofit job). Research of this latter nature is critical to theory building about how we understand commitment in the nonprofit sector, because we have found that nonprofit sector commitment does, in fact, change over time and may not be an enduring fidelity (citation redacted for peer review). Moreover, COVID-19 has been described as a "career shock" since the "pandemic is a highly disruptive and extraordinary event" (Akkermans, Richardson, \& Kraimer, 2020).

There is evidence that individuals reexamining the meaning of work following dramatic events such as 9/11 trigger for some "a desire" to do "meaningful, fulfilling work that contributes to the world in a more direct way" (Wrzesniewski, 2002, p. 233), thus altering or even initiating commitment to the nonprofit sector. In the context of our inquiry here, the pandemic may lead individuals outside the nonprofit sector to evaluate the significance of what they do potentially leading them to find nonprofit jobs that fit this new calling. In this case, their increased commitment to meaningful work induces them to seek employment in the nonprofit sector. For others already working in the sector, the pandemic may reaffirm or increase their commitment to nonprofit work. Nonprofit workers in the current workforce may have experienced the Great Recession or 9/11, but the fatigue experienced under the protracted pandemic at all levels - international, national, systems, even personal - also make it unprecedented and "extraordinary." The sector, nonprofit workplaces, and nonprofit workers have experienced organizational changes and adaptations unforeseen during previous critical incidents, such as social distancing adaptations for programming, universal work-from-home practices, and the personal demands of parenting in a pandemic with virtual school. Thus, the impact of the pandemic will hold reverberations both in the short- and long-term for workers in the nonprofit sector that is critical to understand.

Organizational change theory and research focuses on how individuals react to and make meaning of change and therefore lends itself as a second, overlapping, theoretical lens. Employee reactions to change are multifaceted and can be affective, cognitive, or behavioral (Oreg, Vakola, \& Armenakis, 2011). Those reactions are dependent on the change content, the nature of the change, as well as the change process (Oreg et al., 2011). Employee reactions are important for the success of organizational changes as those are directly related to work-related outcomes (e.g., job satisfaction, commitment, and performance) (Oreg et al., 2011). Employees also react to changes outside of the workplace. Therefore, it is important to consider both organizational-related changes alongside those happening in the social, political, and 
environmental spheres that could have significant impacts on individual's lives resulting in changes in their sector commitment.

Individuals experience change as emotional episodes and engage in sensemaking about changes (Bartunek, Rousseau, Rudolph, \& DePalma, 2006; Oreg, Bartunek, Lee, \& Do, 2018). As Vince and Broussine (1996, p. 4) described, "change depends as much on comprehending and managing emotional relatedness as it does on employing rationality or logic to solve problems," and those emotions may include a "defense mechanism against anxiety." The emotions and meanings ascribed to change events may have tangible impacts on the individual such as their well-being, health, or withdrawal (Oreg et al., 2011). Like the critical incident lens, organizational change literature infers sectoral (and therefore career) shocks will impact individuals' career trajectories and emphasizes the impact is influenced by the meaning the individual ascribes to the shock. Again, nonprofit workers have been made to make sense of global, national, or local traumas in the past, but COVID-19 has posed a new scale and time horizon as the persistent nature of pandemic has caused workers to adjust in the face of uncertainty and persist in their efforts for an indefinite time horizon. How workers are making sense of their current circumstances as well as looking beyond will hold insights for the future of the resilient sector.

\section{3 | PROSPECTS FOR RESEARCH}

The nonprofit sector cannot weather the pandemic's storm without employees who are committed to the sector and the missions the sector serves. Thus, we outline in the following a research agenda about how sector commitment overlaid with the lenses of critical incidents, sensemaking, and reactions to change affords a promising means to investigate how nonprofit workers are personally and professionally navigating the effects of the pandemic. This research agenda focuses on COVID-19 as a workplace crisis impacting nonprofit workers. Whereas emerging research helps us to understand the impact of the pandemic on the sector at large, we argue it is necessary to unpack nonprofit workers' perceptions and experiences during the pandemic as this may shape their future commitment to the sector and have reverberating effects for the stability of the future nonprofit workforce. Research centering on the worker perspective is crucial in helping organizations attract and retain (or perhaps even bring back) workers as well as furthers our theoretical understanding by offering a contemporary perspective on nonprofit sector commitment. COVID-19 intersects the social, political, organizational, and personal, and the sensemaking nonprofit workers ascribe to this incident may affect how they view their work and commitment to the sector. Among these urgent and promising research inquiries, we identify the following practical and theoretical threads that would shed light on how workers think of their current and future work in the sector.

\section{1 | Human resource policy}

Changes such as altered work hours, reductions in pay, layoffs, furloughs, leave options, revised work expectations, and new demands for critical services may impact how nonprofit workers reflect on their current and future work in the sector. Documenting the changes that nonprofit workers have experienced is an important first step toward understanding the scope of COVID-19's impact on the sector's workforce. Individual local and state sectors, such as Young 
et al. (2020) in San Diego, have endeavored to provide some of this documentation, but to-date no national study has been undertaken. A national large-n random sample of nonprofits cutting across various subsectors would afford this broader vantage point and provide opportunity to understand geographic and mission-related variations in these adaptations and responses. Respondents to such inquiry would inform from the organizational level as well as offer individual-level insights about how they view these unfolding changes as benefits and consequences to their continued work in the sector. Another approach could be to inquire directly to workforces of singular or groupings of similar organizations to understand in-depth how workers view policy and process changes enacted in response to COVID-19 and reflect on them from a personal and professional perspective. This research disentangles how human resource practices are designed from how they are perceived, a distinction that impacts organizational outcomes (Wang, Kim, Rafferty, \& Sanders, 2020). Research should investigate sensemaking of workplace policies and organizational changes and the commitment of current and displaced nonprofit workers to the sector over time. Furthermore, we suggest that both organizational and individual level inquiries are needed to understand both short- and long-term impacts of COVID-19 on the nonprofit workforce.

\section{2 | Reactions to change}

We posit the need of a specific study of employee reactions to change outside of the specific HR context. This broader lens would allow researchers to capture reactions to workplace changes not directly related to the workforce policies: organizational changes triggered by COVID-19 are vast and can range from introducing new safety protocols to the daily work flow (e.g., food pantries introducing windows for individuals to visit or move to drive through) to creating new programs in response to the pandemic likely resulting in different work tasks, reassignment of work or other forms of restructuring. As we know from research on appraisal theory, a situation, event, or workplace change can elicit and differentiate emotions based on an employee's evaluation of its personal significance (Scherer, 1999). Given this, nonprofit research needs a better understanding of how employees react to those changes, because it is employees who implement changes on a dayto-day operational basis. Employees' reactions to organizational change matter as their reactions impact the success of change. If nonprofit managers knew more about how their employees feel, think, and behave during the implementation of change, they can adjust their communication and planning accordingly. Studies focusing on the same change (large or small) across organizations would be especially helpful. Research on such organizational changes may also reflect the degree to which nonprofit workers feel they have control over the organizational processes and programs of which they are directly involved with and the degree to which their perspectives and expertise are considered as part of the decision-making processes.

\section{3 | Leadership development}

The nonprofit sector has been criticized for giving insufficient attention to career ladders, labeled a "leadership development deficit" (Landles-Cobb, Kramer, \& Milway, 2015). This inattention has been identified as a cause of weakened sector commitment in some instances given that it engenders a perception of limited career opportunities (Johnson \& Ng, 2016). In the wake of COVID-19, we identify an urgent need to understand how nonprofits, at a minimum, 
sustain and, at best, capitalize on the commitment of workers in order to fulfill the sector's management and leadership needs. Viewing COVID-19 as a critical incident, we do not yet know if the exhaustion brought on by the sustained attention and concern to social distancing and safe community practices have reoriented nonprofit workers from their professional goals to a concern for personal safety and security. We also pose that with resources being directed to urgent operational needs spurred on by COVID-19, administrative capacity will be neglected, which will likely compound the nonprofit sector's leadership deficit. Organizational attention is stretched thin in attending to leadership development in the face of the pandemic, and research attention should supplement by examining where career ladders were broken by COVID-19, as well as where new pathways might emerge, such as those with fresh commitment to the sector perhaps emerging from the for-profit sector, also facing its own set of related but distinct workforce effects. With leadership positions already being difficult to obtain, especially for women and people of color (Lee, 2019), research and practitioners alike should be attentive to career paths that adjust and emerge in the wake of COVID-19 as workers seek advancement and security. We find this last point to be of particular importance given the overlap of the pandemic with the awakening in the United States to systemic racism, and that inattention to the experience of nonprofit workers may be detrimental for the sector's capacity to attract, retain, and develop nonprofit workers of color.

\section{4 | Generational differences}

Millennial and even younger workers may think differently of their work, their interest in nonprofit career options, and commitments than prior generations (Carman, Leland, \& Wilson, 2010; Johnson \& Ng, 2016) while also experiencing the career shock from the pandemic differently (Akkermans et al., 2020). With fewer years of experience, younger workers may make sense of COVID-19 in a way not shared by older workers in the nonprofit sector who have more life and work experience to draw upon, including having worked through previous crisis events such as 9/11, the Great Recession, etc. With the need to identify future leadership for the sector, we see a need for specific research addressing the experience as well as career choices and paths of younger nonprofit workers. Research that uses nonprofit worker age as a control variable, as well as research specifically sampling from younger groups, such as from the Young Nonprofit Professionals Network will help elucidate the nature of generational differences in navigating through the pandemic and thinking about their future work in the sector.

\section{5 | Gender effects}

Human resource research broadly and specific to the nonprofit sector has accrued evidence about how hygiene factors, including family friendly policies, engender employee satisfaction (Weisberg \& Dent, 2016). The personal demands COVID-19 places on working families for homeschool and child care necessitate understanding how the presence, absence, or introduction of such hygiene factors and specifically family friendly policies have affected the professional outlooks of nonprofit workers. Particularly for women, who have been noted by other emerging research for contributing the preponderance of childcare during stay-at-home orders and ongoing school closure (Alon, Doepke, Olmstead-Rumsey, \& Tertilt, 2020), we are curious how they have fared professionally and foresee readjusting after COVID-19. For example, have 
women opted to reduce work hours since the start of the pandemic and has this affected how they think of their career and sector commitment beyond the pandemic? Are the career interests and sector commitments of females altered differently than that of their male counterparts? We also see opportunity to disentangle the role of gendered leadership at both the board and executive levels played in the policies and practices organizations undertaken during the pandemic, and in doing so making the case for how gender representation translates into organizational processes and outcomes for organizations and their workers.

\section{6 | Mission-specific workforce effects}

As COVID-19 has unfolded, nonprofits have been affected differently. While some have provided critical responses such as social services and health care, others have been forced to go dormant as their operations were deemed nonessential and/or social distancing precludes business-as-usual. Early evidence bears this out as Kim and Mason (2020) documented how arts and culture organizations were more severely impacted by COVID-19 from a financial management perspective than human service organizations. Similarly, the impact of job losses caused since the start of the pandemic is uneven across nonprofit fields given the nature of the pandemic; whereas health care has the lowest job losses $(-3.7 \%)$, arts, entertainment, and recreation suffered the higher loses $(-34.2 \%$, Newhouse, 2020a). In light of these variations, research into nonprofit workforce issues should not take a one-size-fits-all approach. Instead, research should be specific to how changes unfolded for specific mission areas, appreciating that those working on the front lines and those forced to the side lines have been impacted differently, and thus, workforce effects brought on by COVID-19 may be mission-specific. Furthermore, sector commitment has been evaluated as a uniform concept for the nonprofit sector in that all workers think uniformly about their work in the sector. However, the uneven impacts of COVID-19 provide a lens to understand variations in how workers in different mission subsectors think of their prospective work in the sector.

\section{7 | Nonprofit graduate education}

Recognizing the growth of nonprofit management education and building upon prior research (Mirabella, Hoffman, Teo, \& McDonald, 2019), we propose studying the impact of COVID-19 on nonprofit workers who are alumni of nonprofit graduate degree programs. By the very choice of their graduate degree, these alumni have demonstrated selection into and commitment to the nonprofit sector (Kuenzi, Stewart, \& Walk, 2020). Furthermore, we know that these graduates are not only committed to serving the sector but also qualified with the competencies and skills needed for management roles as a result of this training (Mesch, 2010). Hence, we identify opportunity for nonprofit graduate program administrators and other researchers to investigate the impact of the pandemic on their alumni's work and career intentions. Given prior research indicating the importance of career competencies on employability and work engagement as well as resilience (Akkermans, Brenninkmeijer, Schaufeli, \& Blonk, 2015), we propose to focus on the competencies alumni have acquired during their programs, how these competencies served (or did not serve) them during the pandemic, and the subsequent impact on their commitment to working in the sector following the pandemic given that is the degree they hold. Such inquiry could offer insight about how nonprofit education prepares a resilient 
sector, as well as how nonprofit education should adapt to the realities of the sector. Moreover, a comparative group of workers in the sector who do not hold a nonprofit-related degree would provide a contrast for distinguishing the utility of a nonprofit graduate degree in the reality of a pandemic-stricken sector, both for the graduates themselves, but also for their organizations and the broader sector.

\section{4 | CONCLUSION}

The ripple effects of COVID-19 have rattled our national and individual senses of security. Broadly speaking, the nonprofit sector has stepped up in a variety of essential capacities, and even for those operating akin to business as usual, their operating environments and constraints have changed. For nonprofit workers, especially younger ones who have limited personal and professional experience to draw upon, COVID-19 may have jarring implications for years to come-a moment of before and after for many in how they see their world and their work in the nonprofit sector. We pose that investigating factors that engender as well as detract from sector commitment for nonprofit workers is important to ensuring the stability of the nonprofit workforce, a critical element for the sector's resiliency in a post-pandemic world.

In order to stabilize and continue to invest in the human resources the sector relies upon, we urge those who study public or nonprofit human resources to take up a thread of research that we have suggested herein. Drawing upon critical incident as well as organizational change theory, this proposed research understands nonprofit workers as making their commitment to their work and the sector under different pre-pandemic circumstances, and now in light of the pandemic's affects at all levels including the personal, organizational, and societal, we need to revisit afresh how these workers make sense of their work and see the pandemic as shaping their future commitment to the sector and the missions it serves. Taken together this research will help the nonprofit sector understand how COVID-19 reshaped the nonprofit sector's workforce and what is needed to engender the commitment of the nonprofit workforce beyond the pandemic.

\section{ACKNOWLEDGEMENTS}

We express gratitude for the funding support of the 2020 RGK-ARNOVA President's Award. We also would like to thank Ashabul Alam, Gage Beck, Abby Klippel, and Emily Peterson for their support as research assistants on this project, as well as extend our appreciation to the reviewers of this manuscript. Marlene Walk would like to thank the Office of the Vice Chancellor for Research at IUPUI for their generous support.

\section{CONFLICT OF INTEREST}

The authors of this article certify that they have no affiliations with or involvement in any organization or entity with any financial interest or nonfinancial interest in the subject matter or materials discussed in this manuscript.

\section{DATA AVAILABILITY STATEMENT}

No data is used in the preparation of this manuscript

\section{ORCID}

Amanda J. Stewart (D) https://orcid.org/0000-0001-5738-1324

Marlene Walk (D) https://orcid.org/0000-0002-1396-9481 


\section{REFERENCES}

AbouAssi, K., McGinnis Johnson, J., \& Holt, S. B. (2019). Job mobility among millennials: Do they stay or do they go? Review of Public Personnel Administration, 1-31. https://doi.org/10.1177/0734371X19874396

Akkermans, J., Brenninkmeijer, V., Schaufeli, W. B., \& Blonk, R. W. B. (2015). It's all about CareerSKILLS: Effectiveness of a career development intervention for young employees. Human Resource Management, 54(4), 533-551. https://doi.org/10.1002/hrm.21633

Akkermans, J., Richardson, J., \& Kraimer, M. (2020). The Covid-19 crisis as a career shock: Implications for careers and vocational behavior. Journal of Vocational Behavior, 119. https://doi.org/10.1016/j.jvb.2020. 103434

Alon, T. M., Doepke, M., Olmstead-Rumsey, J., \& Tertilt, M. (2020). The impact of COVID-19 on gender equality (no. w26947). National Bureau of Economic Research.

Bartunek, J. M., Rousseau, D. M., Rudolph, J. W., \& DePalma, J. A. (2006). On the receiving end: Sensemaking, emotion, and assessments of an organizational change initiated by others. The Journal of Applied Behavioral Science, 42(2), 182-206.

Berkshire, J. C. (2012). Fledgling nonprofit workers bear financial burdens. Chronicle of Philanthropy, 24(15) Retrieved from. https://www.philanthropy.com/article/Fledgling-Nonprofit-Workers/156347

BoardSource. (2020). How nonprofits and board members can respond to COVID-19. Retrieved from https:// boardsource.org/resources/nonprofit-board-member-respond-covid-19/

Bright, J. E., Pryor, R. G., \& Harpham, L. (2005). The role of chance events in career decision making. Journal of Vocational Behavior, 66(3), 561-576.

Carman, J. G., Leland, S. M., \& Wilson, A. J. (2010). Crisis in leadership or failure to plan? Insights from Charlotte, North Carolina. Nonprofit Management and Leadership, 21(1), 93-111.

Flanigan, S. T. (2010). Factors influencing nonprofit career choice in faith-based and secular NGOs in three developing countries. Nonprofit Management \& Leadership, 21, 59-75.

Johnson, J. M., \& Ng, E. S. (2016). Money talks or millennials walk the effect of compensation on nonprofit millennial workers sector-switching intentions. Review of Public Personnel Administration, 36(3), 283-305.

Kim, M., \& Charbonneau, É. (2018). Caught between volunteerism and professionalism: Support by nonprofit leaders for the donative labor hypothesis. Review of Public Personnel Administration, 40(2), 327-349. https:// doi.org/10.1177/0734371X18816139

Kim, M., \& Mason, D. P. (2020). Are you ready: Financial management, operating reserves, and the immediate impact of COVID-19 on nonprofits. Nonprofit and Voluntary Sector Quarterly, 49(6), 1191-1209.

Kuenzi, K., Stewart, A. J., \& Walk, M. (2020). Nonprofit graduate education: Who gets the degree and why? Journal of Public Affairs Education, 26(1), 11-30.

Landles-Cobb, L., Kramer, K., \& Milway, K. S. (2015). The nonprofit leadership development deficit. Stanford Social Innovation Review.

Lee, Y. J. (2019). Scarce as hen's teeth: Women CEOs in large nonprofit organizations. Nonprofit Management and Leadership, 29(4), 601-610.

Linscott, K. G. (2011). Filling the leadership pipeline: Driving forces and their effect on the next generation of nonprofit leaders. SPNHA Review, 7(1), 4.

Mesch, D. J. (2010). Management of human resources in 2020: The outlook for nonprofit organizations. Public Administration Review, 70(S1), S173.

Miller, S. (2020). Employers' health costs could rise 6\% in 2020. Retrieved from https://www.shrm.org/ resourcesandtools/hr-topics/benefits/pages/2020-large-employer-health-costs-expected-to-rise.aspx

Mirabella, R., Hoffman, T., Teo, T., \& McDonald, M. (2019). The evolution of nonprofit management and philanthropic studies in the United States: Are we now a disciplinary field? Journal of Nonprofit Education and Leadership, 9(1), 63-84.

Nelson, E. K. (2018). They pay people to work here? The role of volunteering on nonprofit career awareness and interest. Journal of Public and Nonprofit Affairs, 4(3), 329-349.

Newhouse, C. (2020a). Nonprofit jobs rebound slightly in October, bur remain down by over 900,000 compared to pre-COVID levels. Center for Civil Society Studies, Johns Hopkins University. Retrieved from http://ccss.jhu. edu/october-jobs/ 
Newhouse, C. (2020b). Nonprofit job recovery rate drops to 1.9\% in November, Coult take 2.3 years to fully recover. Center for Civil Society Studies, Johns Hopkins University. Retrieved from http://ccss.jhu.edu/wp-content/ uploads/2020/12/NEWS-RELEASE-Nov-Jobs-Report_12-15-2020.pdf

Ng, E. S., \& McGinnis Johnson, J. (2019). Game of loans: The relationship between education debt, social responsibility concerns, and making a career choice in the public, private, and nonprofit sectors. Nonprofit and Voluntary Sector Quarterly, 49(2), 292-315.

Oreg, S., Bartunek, J. M., Lee, G., \& Do, B. (2018). An affect-based model of recipients' responses to organizational change events. Academy of Management Review, 43(1), 65-86.

Oreg, S., Vakola, M., \& Armenakis, A. (2011). Change recipients' reactions to organizational change a 60-year review of quantitative studies. The Journal of Applied Behavioral Science, 47(4), 461-524.

Salamon, L. M. (2003). The resilient sector: The state of nonprofit America. Washington, DC: Brookings Institution Press.

Salamon, L. M., \& Newhouse, C. L. (2019). The 2019 nonprofit employment report. Center for Civil Society Studies, Johns Hopkins University. Retrieved from http://ccss.jhu.edu/wp-content/uploads/downloads/2019/01/ 2019-NP-Employment-Report_FINAL_1.8.2019.pdf

Salamon, L. M., \& Newhouse, C. L. (2020). The 2020 nonprofit employment report. Center for Civil Society Studies, Johns Hopkins University. Retrieved from http://ccss.jhu.edu/wp-content/uploads/downloads/2020/06/ 2020-Nonprofit-Employment-Report_FINAL_6.2020.pdf

Scherer, K. R. (1999). Appraisal theory. In T. Dalgleish \& M. J. Power (Eds.), Handbook of cognition and emotion (pp. 637-663). West Sussex, England: John Wiley \& Sons Ltd.. https://doi.org/10.1002/0470013494.ch30

Schlosser, F., McPhee, D. M., \& Forsyth, J. (2017). Chance events and executive career rebranding: Implications for career coaches and nonprofit HRM. Human Resource Management, 56(4), 571-591.

Simo, G., \& Bies, A. L. (2007). The role of nonprofits in disaster response: An expanded model of cross-sector collaboration. Public Administration Review, 67, 125-142.

Stewart, A. J., \& Kuenzi, K. (2018). The nonprofit career ladder: Exploring career paths as leadership development for future nonprofit executives. Public Personnel Management, 47(4), 359-381.

Tschirhart, M., Reed, K. K., Freeman, S. J., \& Anker, A. L. (2008). Is the grass greener? Sector shifting and choice of sector by MPA and MBA graduates. Nonprofit and Voluntary Sector Quarterly, 37, 668-688.

Vince, R., \& Broussine, M. (1996). Paradox, defense and attachment: Accessing and working with emotions and relations underlying organizational change. Organization Studies, 17(1), 1-21.

Walk, M., Schinnenburg, H., \& Handy, F. (2014). Missing in action: Strategic human resource management in German nonprofits. VOLUNTAS: International Journal of Voluntary and Nonprofit Organizations, 25(4), 991-1021.

Walk, M., Stewart, A. J., \& Kuenzi, K. (2020). Should I stay or should I go? Investigating nonprofit sector commitment among nonprofit education alumni. Journal of Nonprofit Education and Leadership online first.

Wang, Y., Kim, S., Rafferty, A., \& Sanders, K. (2020). Employee perceptions of HR practices: A critical review and future directions. The International Journal of Human Resource Management, 31(1), 128-173.

Weisberg, M., \& Dent, E. (2016). Meaning or money? Non-profit employee satisfaction. Voluntary Sector Review, 7(3), 293-313.

Weisbrod, B. A. (1988). The nonprofit economy. Cambridge, MA: Harvard University Press.

Wrzesniewski, A. (2002). "It's not just a job" shifting meanings of work in the wake of 9/11. Journal of Management Inquiry, 11(3), 230-234.

Young, E., Deitrick, L., Tinkler, T., Meschen, C., Strawser, C., Funderburk, T., \& Abruzzo, T. (2020). Unprecedented disruption: COVID-19 impact on San Diego nonprofits. Nonprofit Sector Issues and Trends. 5. Retrieved from https://digital.sandiego.edu/npi-npissues/5

\section{AUTHOR BIOGRAPHIES}

Kerry Kuenzi is an Assistant Professor the University of Wisconsin-Green Bay. She researches and publishes on public and nonprofit management topics including nonprofit executive careers, public and nonprofit education, and collaboration and networks. Kerry has her $\mathrm{PhD}$ in public affairs from the University of Colorado, Denver. 
Amanda J. Stewart is an Associate Professor at North Carolina State University in the School of Public and International Affairs, Department of Public Administration. Her research centers on nonprofit organizations, including leadership continuity, career development, and organizational capacity. Amanda received her $\mathrm{PhD}$ in publication administration from American University.

Marlene Walk is an Assistant Professor at the Paul H. O'Neill School of Public and Environmental Affairs at IUPUI. Her research interests are human resource management, volunteering and volunteer management as well as the impact of organizational change on employees. Marlene received her PhD from the School of Social Policy and Practice at the University of Pennsylvania.

How to cite this article: Kuenzi K, Stewart AJ, Walk M. COVID-19 as a nonprofit workplace crisis: Seeking insights from the nonprofit workers' perspective. Nonprofit Management and Leadership. 2021;31:821-832. https://doi.org/10.1002/nml.21465 